\title{
Rescue strategy for advanced liver malignancy with retrohepatic inferior vena cava thrombi: experience to promote surgical oncological benefit
}

\author{
Meng-Hsing Ho ${ }^{1}$, Teng-Wei Chen ${ }^{1}$, Kuang-Wen Oư ${ }^{2}$ Jyh-Cherng $\mathrm{Yu}^{1}$ and Chung-Bao Hsieh ${ }^{1 *}$
}

\begin{abstract}
Background: The prognosis of advanced liver malignancy with inferior vena cava (IVC) thrombi is poor. Many therapeutic policies are challenging for long-term prognosis. We performed the modified effective technique of transdiaphragmatic intrapericardial IVC isolation for curative resection of IVC tumors and prolonged survival time.

Methods: Between 2003 and 2015, 10 patients, sustained liver malignancy with IVC thrombi, underwent surgical intervention. Liver resection with thrombectomy under total hepatic vascular exclusion via the transdiaphragmatic intrapericardial IVC isolation method was performed for these 10 patients. The first 4 patients underwent retrohepatic IVC resection in order to complete resection, and the other 6 patients preserved the retrohepatic IVC. The last 3 patients received preoperative locoregional therapies, and all 10 patients received postoperative adjuvant chemotherapies immediately.

Results: All 10 patients underwent gross en bloc tumor resections with thrombectomy with R0 resection. There was no surgical mortality. Shortening of operation time and reduction of both intraoperative blood loss and hospital stay were demonstrated in the last 6 patients with preserving the retrohepatic IVC. However, similar time to recurrence and survival time were noted in the first 7 patients. The last 3 patients, who had received preoperative locoregional therapies, have better disease-free survival time.

Conclusion: Simplified surgical procedure combined with preoperative locoregional therapies and rapid postoperative adjuvant treatment may provide a greater advantage for these patients.
\end{abstract}

Keywords: Liver malignancy, IVC thrombi, Surgical procedure, Locoregional therapy

\section{Background}

Liver malignancy with inferior vena cava (IVC) thrombi has a poor prognosis [1] and is usually considered terminal. Without curative resection, the long-term prognosis for these patients is dismal. Repeated pulmonary emboli also frequently imperil patients and can cause sudden death. The advances in surgical and anesthetic techniques have made curative surgery feasible for selected patients [2-5]. However, many therapeutic

\footnotetext{
* Correspondence: hmh0208@yahoo.com.tw

${ }^{1}$ Division of General Surgery, Department of Surgery, Tri-Service General Hospital, National Defense Medical Center, Taipei, Taiwan

Full list of author information is available at the end of the article
}

modalities are applied as rescue treatments, such as transarterial chemoembolization (TACE), radiofrequency ablation, or radiotherapy. Adjuvant chemotherapy or target therapy also retards tumor progression. A combination of these therapies seems as the silver lining for patients with advanced liver malignancy if curative surgery is possible.

The difficulties associated with surgical intervention are the invasion of adjacent organs, the various tumor histopathologic types, and the location of thrombus. It is challenging for the surgeon to remove the tumor completely, but this affects the prognosis. Liver resection under total hepatic vascular exclusion (THVE) makes such a complete resection possible [3, 6]. Sternotomy with intra-pericardial IVC isolation has been performed 
to achieve a safe margin and to prevent an embolus from the thrombus. We have previously introduced the technique of transdiaphragmatic intrapericardial IVC isolation for resection of IVC tumors [7]. This method can successfully achieve the resection of gross tumor en bloc and avoid the need for sternotomy and cardiopulmonary bypass. However, what is critical is how to prolong the survival time or time to recurrence. Here, we present our preliminary experience with managing advanced liver malignancy with IVC thrombus.

\section{Methods}

\section{Patients}

Between 2003 and 2015, 10 patients were diagnosed with advanced liver malignancy (8 with hepatocellular carcinoma (HCC), 1 with a leiomyosarcoma, and 1 with an adrenocortical carcinoma) and underwent liver resection with thrombectomy under THVE via the transdiaphragmatic intrapericardial IVC isolation method at the TriService General Hospital in Taiwan. All patients had a tumor thrombus within the retrohepatic IVC, extending near or to the hepatocaval junction (Fig. 1). Four of them underwent resection of the retrohepatic IVC and reconstruction in order to complete resection [7]. Demographic data of the patients in this study are presented in Table 1. There were seven men and three women, with a mean age of 52.8 years (SD 17.7 years; range, 29-86 years). Five patients underwent right lobectomy of the liver, 3 patients underwent extended right

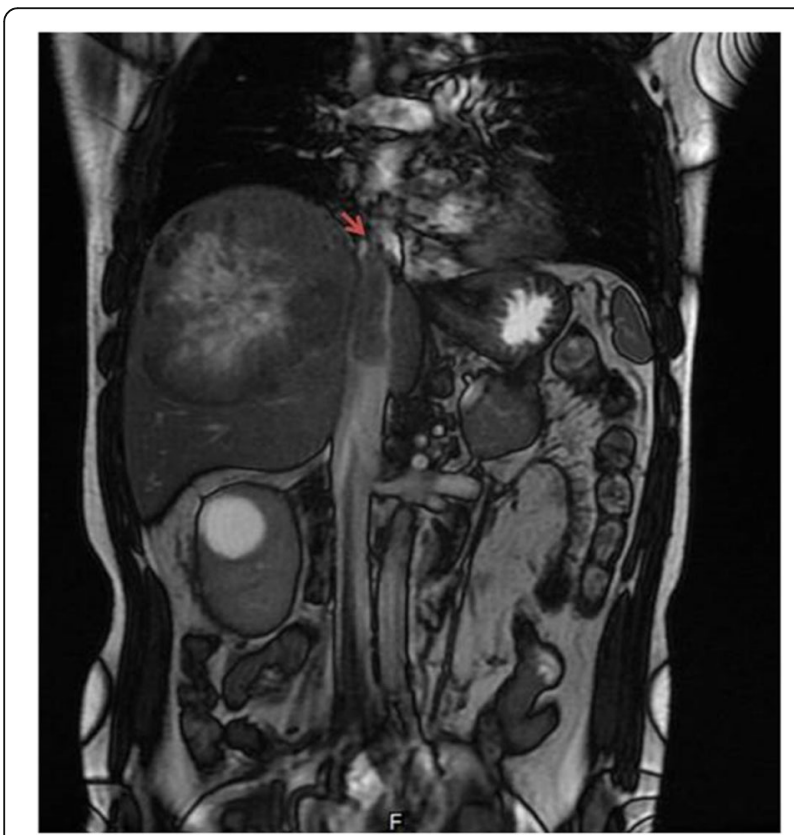

Fig. 1 Magnetic resonance imaging of a patient with hepatocellular carcinoma. The arrow indicates the thrombi reaching the hepatocaval junction lobectomy of the liver, and 2 patients underwent extended left lobectomy of the liver. We used the method of transdiaphragmatic intrapericardial IVC isolation to perform THVE and removed the IVC thrombus via the backflow of the inferior phrenic veins and other collateral vessels. The study was approved by the institutional review board I of Tri-Service General Hospital, National Defense Medical Center (TSGHIRB No. 1-104-05-136).

\section{Preoperative evaluation and management}

Routine preoperative evaluation included liver function tests and tumor markers. The ICG15 test was used if major hepatectomy was inevitable. All patients were further investigated by tissue biopsy, bone scan, or positron emission tomography in order to rule out distal metastasis. Abdominal ultrasonography, abdominal computed tomography $(\mathrm{CT})$, and/or magnetic resonance imaging were performed to assess the resectability of liver lesions. Neoadjuvant chemotherapy, TACE, or radiotherapy was considered in order to decrease the tumor burden. Sorafenib was administered to recent HCC patients for local control of disease progression. Only the last 3 patients received preoperative locoregional therapies. Patients who underwent these locoregional therapies were arranged follow-up dynamic CT scans 1 month later to determine the effect of therapies. Subsequently, operations were arranged if the disease was stable.

\section{Surgical technique}

After the induction of general anesthesia, the patient was placed in the supine position. A reversed L-shaped incision or bilateral subcostal incision with upward extension was made, and the organs within the abdominal cavity were inspected. Transesophageal echocardiography was performed at the same time to delineate the cranial extent of the thrombus.

The plane between the liver and diaphragm was separated carefully. Then, a transdiaphragmatic pericardial window, about $5 \times 5 \mathrm{~cm}$ in diameter, was created, and the intra-pericardial IVC was looped through the window. The liver dissection line was detected under intraoperative ultrasound guidance. A "tumor non-touch" anterior approach with a liver-hanging hepatectomy was performed with or without the Pringles' maneuver, and the IVC was exposed. In order to maintain cardiac input after IVC clamping, a rapid blood transfusion pump and inotropic agents need to be prepared thoroughly. No auto-transfusion device was used in order to avoid tumor metastasis. The central venous pressure was maintained at about $5 \mathrm{~cm} \mathrm{H}_{2} \mathrm{O}$, and the mean arterial pressure was maintained at about $60 \mathrm{mmHg}$ before achieving THVE. THVE was achieved by clamping of the portal trial, intra-pericardial IVC, and infra-hepatic IVC. Thrombectomy via backflow of the inferior phrenic 
Table 1 Demographic data of patients undergoing curative surgery

\begin{tabular}{|c|c|c|c|c|c|c|c|c|}
\hline Patient & Sex & Age $(y)$ & Diagnosis & Child class (score) & Tumor marker & $\begin{array}{l}\text { Location of } \\
\text { hepatic tumor }\end{array}$ & Thrombi location & $\begin{array}{l}\text { Pre-operative } \\
\text { therapy }\end{array}$ \\
\hline 1 & $F$ & 68 & $\begin{array}{l}\text { Leiomyosarcoma of } \\
\text { IVC with liver invasion }\end{array}$ & Non-cirrhosis & N/A & Seg 1,2,3 & $\begin{array}{l}\text { Reaching the } \\
\text { hepatocaval junction }\end{array}$ & $N$ \\
\hline 2 & $F$ & 46 & HBV-related HCC & A (5) & $\begin{array}{l}\text { AFP: } \\
5000 \mathrm{ng} / \mathrm{dL}\end{array}$ & Seg 7,8 & $\begin{array}{l}\text { Near the hepatocaval } \\
\text { junction }\end{array}$ & $\mathrm{N}$ \\
\hline 3 & M & 57 & HBV-related HCC & A (6) & $\begin{array}{l}\text { AFP: } \\
4000 \mathrm{ng} / \mathrm{dL}\end{array}$ & $\operatorname{seg} 5,6,7,8$ & $\begin{array}{l}\text { Reaching the } \\
\text { hepatocaval junction }\end{array}$ & $\mathrm{N}$ \\
\hline 4 & $\mathrm{~F}$ & 38 & $\begin{array}{l}\text { Adrenocortical } \\
\text { carcinoma with liver }\end{array}$ & Non-cirrhosis & N/A & seg $4,5,6,7,8$ & $\begin{array}{l}\text { Reaching the } \\
\text { hepatocaval junction }\end{array}$ & $\mathrm{N}$ \\
\hline 5 & M & 72 & HBV-related HCC & A (5) & $\begin{array}{l}\text { AFP: } \\
>40000 \mathrm{ng} / \mathrm{dL}\end{array}$ & seg $4,5,6,7,8$ & $\begin{array}{l}\text { Near the hepatocaval } \\
\text { junction }\end{array}$ & $\mathrm{N}$ \\
\hline 6 & M & 46 & HBV-related HCC & A (5) & $\begin{array}{l}\text { AFP: } \\
>40000 \mathrm{ng} / \mathrm{dL}\end{array}$ & $\operatorname{seg} 7$ & $\begin{array}{l}\text { Near the hepatocaval } \\
\text { junction }\end{array}$ & $\mathrm{N}$ \\
\hline 7 & M & 29 & HBV-related HCC & A (5) & $\begin{array}{l}\text { AFP: } \\
>40000 \mathrm{ng} / \mathrm{dL}\end{array}$ & seg $5,6,7,8$ & $\begin{array}{l}\text { Near the hepatocaval } \\
\text { junction }\end{array}$ & $\mathrm{N}$ \\
\hline 8 & M & 46 & HBV-related HCC & A (5) & $\begin{array}{l}\text { AFP: } \\
>40000 \mathrm{ng} / \mathrm{dL}\end{array}$ & seg $6,7,8$ & $\begin{array}{l}\text { Reaching the } \\
\text { hepatocaval junction }\end{array}$ & TACE + Sorafenib \\
\hline 9 & M & 86 & $\begin{array}{l}\text { Non-HBV or } \\
\text {-HCV-related HCC, } \\
\text { sacromatoid type }\end{array}$ & A (5) & $\begin{array}{l}\text { AFP: } \\
2.29 \mathrm{ng} / \mathrm{dL}\end{array}$ & $\operatorname{seg} 4$ & $\begin{array}{l}\text { Reaching the } \\
\text { hepatocaval junction }\end{array}$ & TACE + Sorafenib \\
\hline 10 & M & 40 & HBV-related HCC & A (5) & $\begin{array}{l}\text { AFP: } \\
168.5 \mathrm{ng} / \mathrm{dL}\end{array}$ & seg 5,6 & $\begin{array}{l}\text { Reaching the } \\
\text { hepatocaval junction }\end{array}$ & TACE + Sorafenib \\
\hline
\end{tabular}

Mean $\quad 52.8$

SD $\quad 17.7$

AFP alpha-fetoprotein, $H B V$ hepatitis $B$ virus, $F$ female, $H C C$ hepatocellular carcinoma, $H C V$ hepatitis $C$ virus, $M$ male, TACE transarterial chemoembolization

veins was done meticulously, and hepatectomy was subsequently carried out (Fig. 2, Additional file 1: Video S1). Some patients needed to undergo segmental resection of the IVC in order to complete tumor resection. After cleaning the surgical field, another vascular clamp was applied under the junction of the hepatic vein and IVC, and then the intra-pericardial and portal trial clamp were removed to allow liver reperfusion and decrease blood loss from the inferior phrenic vein. The THVE was about $10 \mathrm{~min}$. Finally, peritoneal lavage with distilled water was performed.

Postoperative management and follow-up monitoring After operation, thalidomide or sorafenib was prescribed for patients with $\mathrm{HCC}$, and adjuvant therapies were also applied for other patients persistently if required by the
A

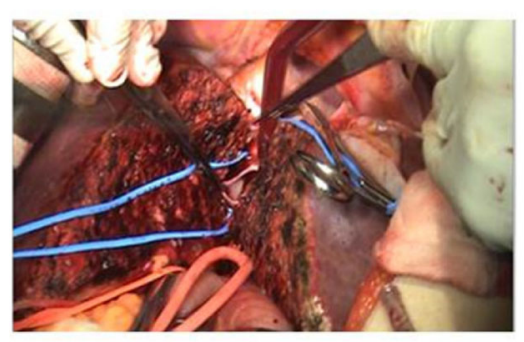

Fig. 2 a Photograph shows thrombectomy via backflow of the inferior phrenic veins under total hepatic vascular exclusion through a transdiaphragmatic pericardial window. b Illustration shows the application of a transdiaphragmatic pericardial window. I inferior phrenic veins, W transdiaphragmatic pericardial window, T IVC thrombi 
condition. All patients received adjuvant therapy after surgery, including monitored for tumor recurrence by abdominal ultrasonography and measurement of tumor markers every month or by CT every 3 months. Suspected intrahepatic recurrence was confirmed by hepatic angiography or dynamic CT. Suspected extrahepatic recurrence was confirmed by elevated tumor marker, positron emission tomography, and tumor biopsy.

\section{Results}

In this study, gross en bloc tumor resection with thrombectomy was performed on all 10 patients. Preoperative, intraoperative, postoperative, and follow-up data for the patients are provided in Table 2 . The mean operative time was $494.4 \mathrm{~min}$ (SD, $201.8 \mathrm{~min}$; range, 302-825 min) and mean blood loss was $1245 \mathrm{~mL}$ (SD, $1004.9 \mathrm{~mL}$; range, $500-3900 \mathrm{~mL}$ ). Perioperative massive bleeding and greater blood transfusion occurred only in the leiomyosarcoma and adrenocortical carcinoma patients. According to Clavien-Dindo classification, three major complications (grade $\geq 3 \mathrm{a}$ ) were observed in 3 patients. Only 1 patient underwent reoperation due to delayed bleeding. All patients underwent a R0 resection. The mean length of hospital stay was 14.6 days (SD, 8.1 days; range, 8-30 days). There was no surgeryrelated mortality. Shortening of the operation time, reduced intraoperative blood loss, and hospital stay were obviously noted in preserved retrohepatic IVC groups.(Table 3) The first 7 patients sustained intrahepatic recurrence and/or distal metastasis several months later and subsequent liver failure, or even death. The last 3 patients are alive and disease-free without events until the present.

\section{Discussion}

The long-term prognosis for advanced liver malignancy, no matter primary or secondary lesions, with IVC thrombus is poor. Patients often manifest pain, IVC obstruction syndrome, and repeating pulmonary emboli. Surgical resection of these tumors is not recommended as a standard treatment, but it should be considered for relieving the symptoms if all other treatment options have been exhausted. However, there was no significant long-term surgical oncological benefit proved in the past study, even if R0 resection was achieved. In our preliminary experience, the combined therapies, including preoperative locoregional therapy, surgical resection with a free margin, and adjuvant therapies as soon as possible postoperatively, might be the only life-saving therapy.

Most of the patients in our center received palliative locoregional treatments [8], such as radiotherapy, TACE, or targeted therapy, and expired abruptly. In contrast, a few patients had good responses to the locoregional therapies. These differences may be attributed to a "selection effect." During palliative treatments, some patients might become despaired due to tumor progression, and thus selecting patients with slower tumor progression, and therefore relatively benign tumor behavior. In addition, the locoregional therapies have been reported to reduce the tumor burden and improve survival rate for HCC patients who are undergoing liver transplant. [9-11] It also makes the operation more smoothly. Subsequently, surgical resection might be considered. After meticulous assessment, attempted curative resection might be performed. In the past, these patients might have undergone such procedures as hepatectomy with or without THVE, IVC resection, sternotomy, or thoracotomy with cardiopulmonary bypass. However,

Table 2 Intraoperative, postoperative, and follow-up data of patients undergoing curative surgery

\begin{tabular}{|c|c|c|c|c|c|c|c|c|c|}
\hline Patient & Surgery & $\begin{array}{l}\text { Operation } \\
\text { time (min) }\end{array}$ & $\begin{array}{l}\text { Blood } \\
\text { loss }(\mathrm{mL})\end{array}$ & $\begin{array}{l}\text { Complication } \\
\text { (CD) }\end{array}$ & $\begin{array}{l}\text { Postoperative tumor } \\
\text { marker (1 month) }\end{array}$ & $\begin{array}{l}\text { Postoperative } \\
\text { hospital stay (days) }\end{array}$ & $\begin{array}{l}\text { Adjuvant } \\
\text { therapy }\end{array}$ & $\begin{array}{l}\text { Disease-free } \\
\text { time (months) }\end{array}$ & $\begin{array}{l}\text { Survival time } \\
\text { (months) }\end{array}$ \\
\hline 1 & $E L L+I+T$ & 825 & 1850 & Illa & N/A & 30 & RT & 3 & 6 \\
\hline 2 & $R L+I+T$ & 725 & 630 & I & AFP 175.5 ng/dL & 10 & Thalidomide & 5 & 9 \\
\hline 3 & $R L+I+T$ & 721 & 850 & $\| l l b$ & AFP 188.5 ng/dL & 29 & Thalidomide & 12 & 15 \\
\hline 4 & $A+E R L+I+T$ & 602 & 3900 & Illa & N/A & 13 & $C T$ & 15 & 17 \\
\hline 5 & $E R L+D+T$ & 402 & 500 & I & AFP 218 ng/dL & 10 & Thalidomide & 8 & 14 \\
\hline 6 & $R L+T$ & 350 & 1000 & $\mathrm{Nil}$ & AFP 450 ng/dL & 12 & Thalidomide & 9 & 17 \\
\hline 7 & $E R L+T$ & 377 & 900 & I & AFP 500 ng/dL & 10 & Thalidomide & 5 & 15 \\
\hline 8 & $R L+T$ & 302 & 1200 & Nil & AFP $12.7 \mathrm{ng} / \mathrm{dL}$ & 8 & Sorafenib & $39+$ & Alive \\
\hline 9 & $E L L+T$ & 328 & 920 & $\|$ & AFP $<0.5 \mathrm{ng} / \mathrm{dL}$ & 15 & Sorafenib & $30+$ & Alive \\
\hline 10 & $R L+T$ & 312 & 700 & $\mathrm{Nil}$ & AFP $5.27 \mathrm{ng} / \mathrm{dL}$ & 9 & Sorafenib & $10+$ & Alive \\
\hline Mean & & 494.4 & 1245 & & & 14.6 & & & \\
\hline SD & & 201.8 & 1004.9 & & & 8.1 & & & \\
\hline
\end{tabular}

ELL extended left lobectomy, I IVC resection, $T$ thrombectomy, $A$ adrenectomy, $D$ partial diaphragm resection, $R L$ right lobectomy, ERL extended right lobectomy, $C D$ Clavien-Dindo classification, N/A no analysis, $R T$ radiotherapy, $C T$ chemotherapy, + the duration to date of article submission 
Table 3 Subgroups of patients undergoing curative surgery and analysis of intraoperative, postoperative, and follow-up data

\begin{tabular}{|c|c|c|c|}
\hline & IVC resection $N=4$ & Preserved IVC N=3 & Preserved IVC+ preoperative palliative treatment $N=3$ \\
\hline $\begin{array}{l}\text { Operation time (min) } \\
\text { Mean (SD) }\end{array}$ & $718.25(91.22)$ & $376.33(26.01)$ & $314(13.11)$ \\
\hline $\begin{array}{l}\text { Blood loss }(\mathrm{mL}) \\
\text { Mean (SD) }\end{array}$ & $1807.5(1492.61)$ & $800(264.58)$ & $940(250.60)$ \\
\hline $\begin{array}{l}\text { Postoperative tumor marker (1 month) } \\
\text { Mean (SD) }\end{array}$ & $\mathrm{N} / \mathrm{A}$ & $389.33(150.47)$ & $6.16(6.15)$ \\
\hline $\begin{array}{l}\text { Postoperative hospital stay (days) } \\
\text { Mean (SD) }\end{array}$ & $20.5(10.47)$ & $10.67(1.15)$ & $10.67(3.79)$ \\
\hline $\begin{array}{l}\text { Disease-free time (months) } \\
\text { Mean (SD) }\end{array}$ & $8.75(5.68)$ & $7.33(2.08)$ & $26.33(14.84)$ at least \\
\hline $\begin{array}{l}\text { Survival time (months) } \\
\text { Mean (SD) }\end{array}$ & $11.75(5.12)$ & $15.33(1.52)$ & $26.33(14.84)$ at least \\
\hline
\end{tabular}

possible surgical complications, residual tumor retention, complicated operation procedures, and long recovery time might cause these patients to be ineligible for the next treatment and to become hopeless.

In our study, liver malignancies with IVC thrombosis were found in the diagnosis of all patients and even extended to the hepatocaval junction. We performed liver resection with thrombectomy under THVE by intrapericardial IVC isolation through a transdiaphragmatic pericardial window. We sought to avoid possible complications related to sternotomy or thoracotomy and diminish patients' fear. At first, we also resected the retrohepatic IVC in order to completely remove the tumor [7]. However, this caused the surgical procedure to be more difficult. Subsequent anticoagulation prescription and possible graft thrombosis also affected patients with postoperative dysfunctional liver. Therefore, we preserved the retrohepatic IVC for the patients and performed thrombectomy via backflow of the inferior phrenic veins and other collateral vessels. These patients seemed to recover more rapidly and to have less worry about surgical procedure-related complications. Initially, the survival time or disease-free time was similar between groups. However, the last 3 patients all received preoperative palliative treatments for reducing tumor burden and relieving symptoms. After observation for 1 month, they underwent surgical intervention if no obvious tumor progression or distal metastasis developed. We noted that the intraoperative blood loss was decreasing and the thrombus seemed solid and non-adherent (Fig. 3). These changes might have been caused by locoregional treatment-related ischemic changes or lipiodol retention. The preoperative locoregional therapies reduced the tumor burden and made the thrombi non-adherent. Attempting complete thrombectomy and detachment of the space between the IVC and tumor became easier. It also effectively shortened the operation time, and no major complication developed. The operation process became more simplified and effective. There is also a trend for prolonged time to recurrence in the last 3 patients.

Our surgical technique is a simplified and effective procedure with an acceptable operation time and amount of blood loss. There was no procedure-related mortality. Most of these patients received adjuvant

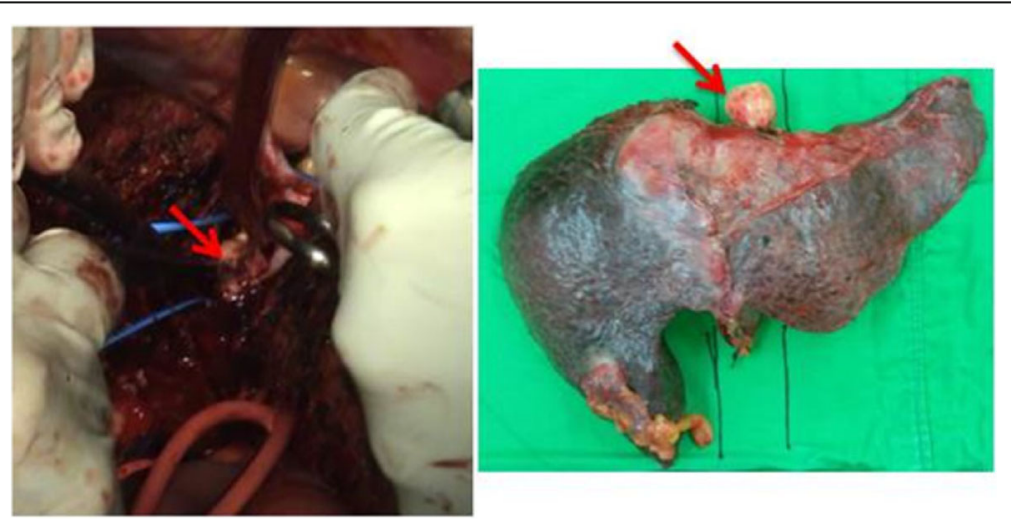

Fig. 3 The arrow indicates the thrombus, which seemed solid and non-adherent 


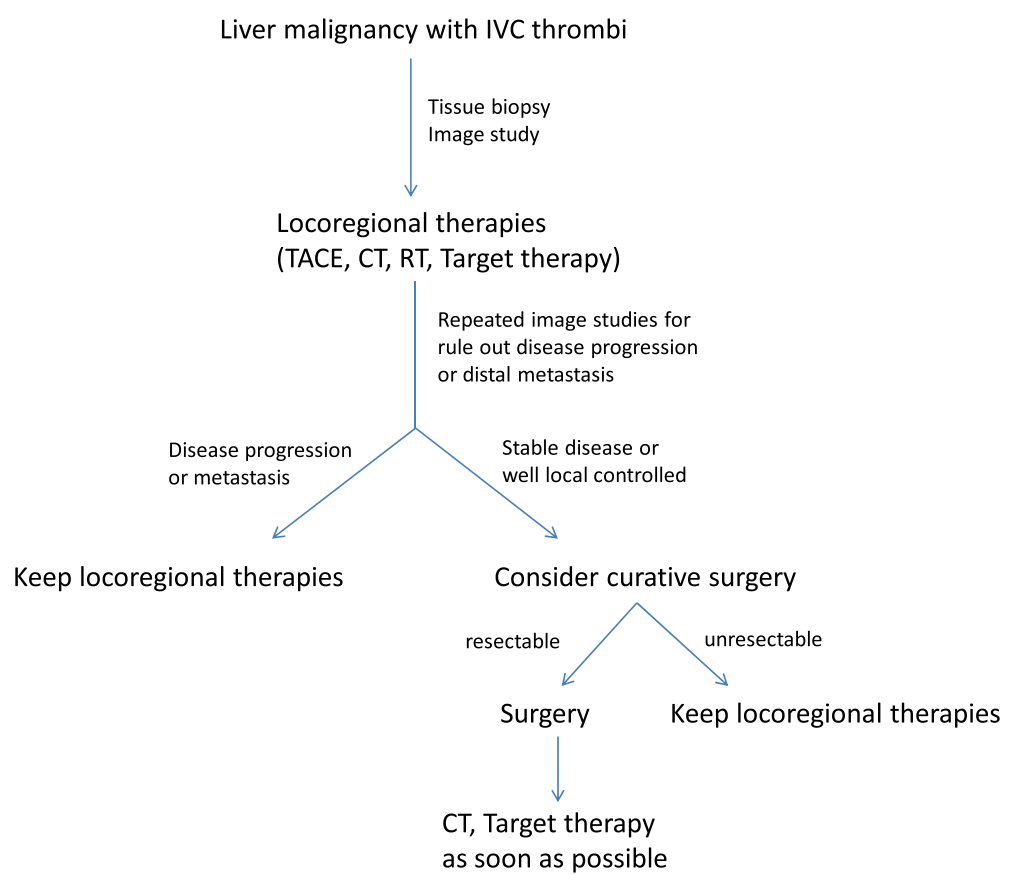

Fig. 4 Flowchart applied in our center for liver malignancy with IVC thrombi. TACE transarterial chemoembolization, CT chemotherapy, RT radiotherapy

treatments about 2 weeks postoperatively. The operation time and hospital stay were shortened considerably. Tumor makers decreased dramatically, and disease-free time or survival time improved, especially in the last 3 patients.

On the basis of various tumor histopathologic types, the prognosis varies slightly. For HCC with IVC thrombi, the survival span is less than 3 months without surgical intervention. For leiomyosarcoma with IVC thrombi, the medial survival is only 1 month without operation. Therefore, survival is usually measured in months in untreated liver malignancy. Palliative treatments are applied to retard disease progression and provide a selection effect. However, many small series have demonstrated a surgical benefit for these patients if the difficulty of the surgical procedure can be overcome $[2,4,12-16]$. In their HCC group, Kokudo et al. [12] demonstrated that IVC thrombosis and R1/2 resection were significant risk factors for recurrence and survival. They also revealed that the mean survival time and time to recurrence in HCC patients with IVC thrombi were 1.39 and 0.25 years respectively. Then, prolonging survival time became the critical issue. From our preliminary experience, a simple and effective surgical procedure combined with preoperative locoregional therapies and rapid postoperative adjuvant treatment may provide more advantages to these patients (Fig. 4). However, this is a small series retrospective study, caused some limitation. Further larger study is needed to clarify the benefit of this therapeutic policy for advanced liver malignancy with retrohepatic IVC thrombi.

\section{Conclusion}

Curative surgical intervention for liver malignancy with IVC thrombus resulted in a survival benefit. The issue of prolonged survival time remains a challenge for physicians. We believe that a simple and effective surgical procedure combined with preoperative locoregional therapies and rapid postoperative adjuvant treatment may provide greater advantage to such patients.

\section{Additional file}

Additional file 1: The video showed a 46-year-old man, who has the HBV related advanced HCCs ( seg $6,7,8$ ) with retrohepatic IVC thrombi, underwent surgical intervention (Liver resection with thrombectomy under total hepatic vascular exclusion via the transdiaphragmatic intrapericardial IVC isolation method). (MP4 31682 kb)

\section{Abbreviations}

CT: Computed tomography; HCC: Hepatocellular carcinoma; IVC: Inferior vena cava; TACE: Transarterial chemoembolization; THVE: Total hepatic vascular exclusion

\section{Acknowledgements}

We thank the patients, who agreed to the presentation in order to advance medical knowledge.

Funding

There is no funding for this study. 


\section{Availability of data and materials}

The dataset supporting the conclusions of this article is included within the article (and its additional file(s)).

\section{Authors' contributions}

$\mathrm{M}-\mathrm{HH}$ and $\mathrm{C}-\mathrm{BH}$ participated in the design of the study and performed the statistical analysis. T-WC, K-WO, J-CY, and M-HH conceived of the study and participated in its design and coordination. M-HH drafts the manuscript.

All authors read and approved the final manuscript.

\section{Competing interests}

The authors declare that they have no competing interests.

\section{Consent for publication}

Not applicable

\section{Ethics approval and consent to participate}

The study was approved by the institutional review board (IRB)/ethics committee of Tri-Service General Hospital, National Defense Medical Center, Taiwan (No. 1-104-05-136). Due to the retrospective study design, written consent was waived by the institutional review board.

\section{Publisher's Note}

Springer Nature remains neutral with regard to jurisdictional claims in published maps and institutional affiliations.

\section{Author details}

'Division of General Surgery, Department of Surgery, Tri-Service General Hospital, National Defense Medical Center, Taipei, Taiwan. ${ }^{2}$ Divisions of Plastic Surgery and General Surgery, Department of Surgery, Tri-Service General Hospital, National Defense Medical Center, Taipei, Taiwan.

Received: 31 October 2016 Accepted: 2 April 2017

Published online: 12 April 2017

\section{References}

1. Thomas MB, Jaffe D, Choti MM, et al. Hepatocellular carcinoma: consensus recommendations of the National Cancer Institute Clinical Trials Planning Meeting. J Clin Oncol. 2010;28(25):3994-4005.

2. Hemming AW, Reed Al, Langham Jr MR, et al. Combined resection of the liver and inferior vena cava for hepatic malignancy. Ann Surg. 2004;239(5): $712-9$.

3. Fu SY, Lau WY, Li AJ, et al. Liver resection under total vascular exclusion with or without preceding Pringle maneuver. Br J Surg. 2010;97(1):50-5.

4. Wakayama K, Kamiyama T, Yokoo H, et al. Surgical management of hepatocellular carcinoma with tumor thrombi in the inferior vena cava or right atrium. World J Surg Oncol. 2013;11:259.

5. Chiche L, Dousset B, Kieffer E, et al. Adrenocortical carcinoma extending into the inferior vena cava: presentation of a 15-patient series and review of the literature. Surgery. 2006;139(1):15-27.

6. Bismuth $\mathrm{H}$, Castaing D. Garden OJ major hepatic resection under total vascular exclusion. Ann Surg. 1989;210(1):13-9.

7. Chen TW, Tsai CH, Chou SJ, et al. Intrapericardial isolation of the inferior vena cava through a transdiaphragmatic pericardial window for tumor resection without sternotomy or thoracotomy. Eur J Surg Oncol. 2007;33(2): 239-42.

8. Liu L, Chen H, Wang M, et al. Combination therapy of sorafenib and TACE for unresectable HCC: a systematic review and meta-analysis. PLoS One. 2014;9(3):e91124.

9. Agopian VG, Morshedi MM, McWilliams J, et al. Complete pathologic response to pretransplant locoregional therapy for hepatocellular carcinoma defines cancer cure after liver transplantation: analysis of 501 consecutively treated patients. Ann Surg. 2015;262(3):536-45.

10. Ciccarelli O, Lai $Q$, Goffette $P$, et al. Liver transplantation for hepatocellular cancer: UCL experience in 137 adult cirrhotic patients. Alpha-foetoprotein level and locoregional treatment as refined selection criteria. Transpl Int. 2012;25(8):867-75.

11. Ho MH, Yu CY, Chung KP, et al. Locoregional therapy-induced tumor necrosis as a predictor of recurrence after liver transplant in patients with hepatocellular carcinoma. Ann Surg Oncol. 2011;18(13):3632-9.
12. Kokudo T, Hasegawa K, Yamamoto $S$, et al. Surgical treatment of hepatocellular carcinoma associated with hepatic vein tumor thrombosis. J Hepatol. 2014;61(3):583-8.

13. Delis SG, Madariaga J, Ciancio G. Combined liver and inferior vena cava resection for hepatic malignancy. J Surg Oncol. 2007;96(3):258-64.

14. Gallagher TK, Udupa KV, Geoghegan JG, et al. Techniques and outcomes of combined inferior vena cava and visceral resection for benign and malignant disease. Int J Surg. 2014;12(8):864-7.

15. Nuzzo G, Giordano M, Giuliante F, et al. Complex liver resection for hepatic tumours involving the inferior vena cava. Eur I Surg Oncol. 2011;37(11):921-7.

16. Azoulay D, Andreani P, Maggi U, et al. Combined liver resection and reconstruction of the supra-renal vena cava: the Paul Brousse experience. Ann Surg. 2006;244(1):80-8.

\section{Submit your next manuscript to BioMed Central and we will help you at every step:}

- We accept pre-submission inquiries

- Our selector tool helps you to find the most relevant journal

- We provide round the clock customer support

- Convenient online submission

- Thorough peer review

- Inclusion in PubMed and all major indexing services

- Maximum visibility for your research

Submit your manuscript at www.biomedcentral.com/submit
C) Biomed Central 